This item was submitted to Loughborough's Research Repository by the author.

Items in Figshare are protected by copyright, with all rights reserved, unless otherwise indicated.

\title{
Evaluation of the skill of North-American multi-model ensemble (NMME) global climate models in predicting average and extreme precipitation and temperature over the continental USA
}

\section{PLEASE CITE THE PUBLISHED VERSION}

http://dx.doi.org/10.1007/s00382-016-3286-1

\section{PUBLISHER}

(C) Springer

\section{VERSION}

AM (Accepted Manuscript)

\section{PUBLISHER STATEMENT}

This work is made available according to the conditions of the Creative Commons Attribution-NonCommercialNoDerivatives 4.0 International (CC BY-NC-ND 4.0) licence. Full details of this licence are available at: https://creativecommons.org/licenses/by-nc-nd/4.0/

\section{LICENCE}

CC BY-NC-ND 4.0

\section{REPOSITORY RECORD}

Slater, Louise, Gabriele Villarini, and Allen Bradley. 2019. "Evaluation of the Skill of North-american Multimodel Ensemble (NMME) Global Climate Models in Predicting Average and Extreme Precipitation and Temperature over the Continental USA". figshare. https://hdl.handle.net/2134/23996. 
9 The authors thank the NMME program partners and acknowledge the help of NCEP, IRI and NCAR 10

\section{Conflict of Interest}

17 The authors declare that they have no conflict of interest. 
Abstract

19 This paper examines the forecasting skill of eight Global Climate Models (GCMs) from the North20 American Multi-Model Ensemble (NMME) project (CCSM3, CCSM4, CanCM3, CanCM4, GFDL2.1,

21 FLORb01, GEOS5, and CFSv2) over seven major regions of the continental United States. The skill of the

22 monthly forecasts is quantified using the mean square error skill score. This score is decomposed to assess

23 the accuracy of the forecast in the absence of biases (potential skill) and in the presence of conditional

24 (slope reliability) and unconditional (standardized mean error) biases. We summarize the forecasting skill

25 of each model according to the initialization month of the forecast and lead time, and test the models' ability

26 to predict extended periods of extreme climate conducive to eight 'billion-dollar' historical flood and

27 drought events.

28 Results indicate that the most skillful predictions occur at the shortest lead times and decline rapidly 29 thereafter. Spatially, potential skill varies little, while actual model skill scores exhibit strong spatial and 30 seasonal patterns primarily due to the unconditional biases in the models. The conditional biases vary little 31 by model, lead time, month, or region. Overall, we find that the skill of the ensemble mean is equal to or 32 greater than that of any of the individual models. At the seasonal scale, the drought events are better 33 forecasted than the flood events, and are predicted equally well in terms of high temperature and low 34 precipitation. Overall, our findings provide a systematic diagnosis of the strengths and weaknesses of the 35 eight models over a wide range of temporal and spatial scales. 


\section{Introduction}

37 The North American Multimodel Ensemble (NMME) is an experimental project which was established in response to the U.S. National Academies' recommendation to support regional climate forecasting and decision-making over intraseasonal to interannual timescales (National Research Council, 2010). Participating North-American agencies, which include the National Oceanic and Atmospheric Administration (NOAA)'s National Centers for Environmental Prediction (NCEP) and Geophysical Fluid Dynamics Laboratory (GFDL), the International Research Institute for Climate and Society (IRI), the National Center for Atmospheric Research (NCAR), the National Aeronautics and Space Administration (NASA)'s Global Modeling and Assimilation Office (GMAO), the Rosenstiel School of Marine \& Atmospheric Science from the University of Miami (RSMAS), the Center for Ocean-Land-Atmosphere Studies (COLA), and Environment Canada's Meteorological Service of Canada - Canadian Meteorological Center (CMC), have been contributing model predictions from their hindcasts (dating back to the early 1980s) and real-time forecasts since August 2011. Each model consists of between 6 and 28 "members," and the forecasts are provided at lead times that range between 0.5 and 11.5 months ahead of the forecast (Table 1). The two key advantages of the NMME, in comparison with other projects, are that the data are made freely available and that the focus is not just on retrospective forecasts, but also on real-time information.

A central component of the NMME project consists in quantifying model ensemble skill (Kirtman et al., 2014) to generate the most reliable climate forecasts. Model accuracy can be measured on several levels, by comparing each model's individual members, each model's ensemble mean (of model members), or the multi-model ensemble mean, against the observed climate data. Typically, multi-model means are found to have greater skill than single models (Hagedorn et al., 2005). Such averaging schemes are usually computed either by giving the same weight to each model's ensemble mean, or by giving equal weight to all members (thus assigning more weight to the models with more members) (e.g., Tian et al., 2014). The first assessments of NMME skill consistently suggest that the multi-model ensemble mean performs as well as, or better than, the best model (Becker et al., 2014, DelSole and Tippett 2014, Wood et al., 2015, Ma et al. 2015a, Thober et al., 2015). This increased skill of the NMME multi-model ensemble in contrast with the individual models appears to be related to the addition of new signals (from new models), rather than to the reduction of noise due to model averaging (DelSole et al., 2014).

However, because of the broad spatial and temporal scope of the NMME, most analyses of model skill are limited by necessity to specific lead times, regions, or seasons. Global, $1^{\circ}$-by $-1^{\circ}$ resolution studies tend to

67 focus either on just one model, or on the shortest available lead time. For instance, Jia et al. (2015) 68 characterize the skill of the high-resolution GFDL model FLOR, while Saha et al. (2014) investigate the 
skill of the NCEP Climate Forecast System (CFSv2) at the global scale. Conversely, Becker et al. (2014) provide a comprehensive analysis of temperature, precipitation, and sea surface temperature forecasts for multiple models at the global scale, but focus mainly on the shortest available lead time. Wang (2014) examines the global skill of NMME precipitation forecasts for the summer months and only at the shortest lead time. Mo and Lettenmaier (2014) interpolate the NMME forecasts bilinearly to a $0.5^{\circ}$ grid over the continental United States to evaluate runoff and soil moisture forecasts, but only up to the 3-month lead time.

In contrast, analyses of the NMME conducted at the sub-continental scale often allow for a more comprehensive examination of model skill and of the relationship between ensemble forecasts and climate oscillations, and reveal regional agreement between models (Infanti and Kirtman 2015). In the southeastern United States, for example, it is shown that temperature and precipitation forecasts become increasingly skillful in the winter months at short lead times (Infanti and Kirtman, 2014). Studies found that the predictability of precipitation (Mo and Lyon, 2015), and/or temperature (Roundy et al., 2015) and drought (Ma et al., 2015b) generally improves in regions that are significantly affected by El Niño-Southern Oscillation (ENSO). In North America, the highest correlations between temperature/precipitation forecasts and observations are found in the south-east (SE), south-west (SW), and north-west (NW) during strong Eastern Pacific El Niño events (Infanti and Kirtman 2015). Such analyses also help determine which models are the most useful at the regional/seasonal scale; for instance, over continental China, the CFS models performed the best, followed by GFDL and NASA, the Canadian models, with the IRI and CCSM3 models in the final position (Ma et al. 2015b) (see Table 1 for an overview of models and acronyms - note that we did not include IRI's fourth-generation atmospheric GCM (ECHAM4p5) in our model selection because it no longer issues real-time forecasts). In an analysis of four NMME models over the continental United States and the Atlantic Warm Pool (AWP), the CFSv2 and GFDL models showed the most skill for predicting seasonal rainfall anomalies in the July-October season (Misra and Li, 2014).

Thus, despite an increasing number of analyses focused on the quantification of NMME models' skill, a systematic investigation across different models, regions, seasons, and lead times is still lacking. Additionally, very little is known regarding the skill of these models for forecasting extended periods of high temperature and/or low precipitation leading to drought conditions, as well as extreme precipitation leading to flooding. For instance, we know that most NMME models were not able to forecast the 2012 North American drought correctly, while those that correctly predicted its occurrence did so fortuitously, and "for the wrong reason" (Kam et al. 2014). Therefore, a thorough evaluation of the NMME models' ability to forecast the occurrence of different extremes over extended periods of time is also missing.

To fill these gaps, the research questions that we address in this study are the following: 
- At the intraseasonal scale, what is the skill of the eight individual NMME model ensembles in predicting precipitation and temperature patterns, for every available lead time, every month of the year, and for every sub-region of the continental United States? How do their biases compare? Do certain models perform better than others for certain regions, lead times, and months, and does the eight-model ensemble mean outperform the individual models?

- At the seasonal scale, what is the ability of these eight models to forecast extended periods of high temperature and low precipitation leading to drought conditions, as well as prolonged periods of extreme precipitation leading to flooding?

To answer these questions, we conduct a systematic decomposition of the forecasting skill of the eight individual model ensembles (computed as the mean of all members in each model) as well as of the eightmodel ensemble mean (computed by assigning the same weight to each model's mean), using the NMME forecast data and observed monthly data for verification. Section 2 presents the forecast and observed data, and Section 3 provides an overview of the statistical methods used to perform forecast verification and the diagnosis of each model's ability to predict seasonal extremes. The results are presented in Section 4, while Section 5 summarizes the main findings and conclusions of the study.

\section{Data}

\subsection{NMME Temperature and Precipitation Data}

Here we focus on eight GCMs from the NMME project, for which temperature and precipitation forecasts are available from the early 1980s to the present. The GCMs we consider are: CCSM3 and CCSM4 from NCAR, COLA and RSMAS; CanCM3 and CanCM4 from Environment Canada's CMC; CM2.1 and FLORb01 from NOAA's GFDL; GEOS5 from NASA's GMAO; CFSv2 from NOAA's NCEP. The characteristics of the different models are summarized in Table 1. Of these models, CCSM3 and CCSM4 are from Phase I of the NMME project, while all of the others are from Phase II.

The data were downloaded from the IRI/Lamont Doherty Earth Observatory (LDEO) Climate Data Library (http://iridl.ldeo.columbia.edu/) in netCDF format, on a $1.0^{\circ}$ latitude by $1.0^{\circ}$ longitude grid. Monthly total precipitation (variable name "prec", in $\mathrm{mm} / \mathrm{day}$ ) and monthly reference mean temperature at 2 meters (variable name "tref", in Kelvin units) were obtained for all available lead times and ensemble members over the continental United States. Temperature data were converted from Kelvin units to degrees Celsius. For CanCM3, CanCM4, and CFSv2, the hindcast and forecast data were downloaded separately and combined for the analysis. In the case of CFSv2 we used the pentad realtime forecasts which match the pattern of the CFSv2 hindcasts. 
Data were extracted for each model from netCDF files in R using the ncdf4 package (Pierce, 2014). The files typically contain five dimensions, which are the longitude, latitude, member, lead, and forecast reference time. The number of ensemble members ranges from 6 for COLA to 12 for GEOS5 and FLORb01, and 28 for CFSv2 (Table 1). To limit the scope of the analysis, we consider the mean of each model's ensemble members, rather than analyze each model member individually. The focus of our analysis is monthly to seasonal predictions, ranging from 0.5 to 11.5 month leads. The term "lead" indicates the period between the forecast initialization time and the month that is predicted (so a " 0.5 -month lead forecast" refers to a monthly forecast that was made about 15 days ahead of the forecast period). Model forecast lead times vary from 0.5-9.5 months for GEOS5, and up to 11.5 months for all of the other models (Table 1). Here, the expression "forecast reference time" refers to the date when the forecasts were issued (e.g., July 2015).

To analyze forecast skill at the regional scale, we define seven major regions of the United States based on the boundaries described in Kunkel et al. (2013), which are a modification of the regions that were originally used in the 2009 National Climate Assessment Report (Karl et al., 2009) by dividing the Great Plains Region into North and South (Figure 1). The NMME data are projected as stacked rasters and cropped to the dimensions of these seven regions using the 'raster' package in R (Hijmans, 2015), to extract the mean weighted forecast value of all of the grid cells falling within each region (as defined by the polygons) for every month and lead time.

\subsection{Reference Temperature and Precipitation Data}

To verify model skill, we use temperature and precipitation data from the Parameter-elevation Regression on Independent Slopes Model (PRISM) climate mapping system (Daly et al. 2002), which represents the reference dataset for the continental United States. PRISM's temporal and spatial resolutions are monthly and approximately $4 \mathrm{~km}$. The data are freely available from the web (http://www.prism. oregonstate.edu/index.phtml) and cover the period from 1890 to the present. We divide precipitation monthly totals by the number of days in each historical month to obtain daily values, and to match the units of the NMME models. Extracted precipitation and temperature data time series are plotted against reference PRISM data for every model, region, month, and lead time for verification purposes (see Supplementary materials, pp.2-25).

Other studies (e.g., Becker et al., 2014, Infanti and Kirtman, 2014) have used as verification field the station observation-based Global Historical Climatology Network and Climate Anomaly Monitoring System (GHCN+CAMS) for temperature, and the Climate Prediction Center (CPC) global daily Unified Raingauge Database (URD) gauge analysis for precipitation rate. Here we chose to use PRISM data instead because 
they account for elevation in the interpolation scheme and have a fine spatial resolution. Moreover, they are the official product for the U.S. Department of Agriculture.

\section{Methodology}

\subsection{Forecast verification}

Different approaches and methods have been developed to quantify the skill of a forecast system. Here we quantify the accuracy of the forecast relative to the climatology (used as reference) using the mean square error (MSE) skill score $S S_{M S E}$ (e.g., Hashino et al. 2007):

$S S_{M S E}=1-\frac{M S E}{\sigma_{x}^{2}}$

where $\sigma_{x}$ represents the standard deviation of the observations. A perfect forecast receives a skill score of 1. As the value tends to zero, the forecast skill decreases. A value of 0 indicates that the forecast accuracy is the same as what we would achieve using climatology as our forecast. Negative values indicate that the accuracy is worse than the climatology forecast. The value of $S S_{M S E}$ can be decomposed into three components (Murphy and Winkler 1992):

$S S_{M S E}=\rho_{f x}^{2}-\left[\rho_{f x}-\frac{\sigma_{f}}{\sigma_{x}}\right]^{2}-\left[\frac{\mu_{f}-\mu_{x}}{\sigma_{x}}\right]^{2}$

where $\rho_{f x}$ is the correlation coefficient between observations and forecasts and quantifies the degree of linear dependence between the two; $\mu_{f}$ and $\mu_{x}$ are the forecast and observation means, respectively; $\sigma_{f}$ represents the standard deviation of the forecasts. Based on this decomposition, the value of the correlation coefficient (or its squared counterpart, the coefficient of determination) reflects the forecast accuracy only in the absence of biases. For this reason, it represents the potential skill (PS), which is the skill we could achieve if there were no biases. Without the quantification of the biases, the forecast skill is inflated. Thus, it is commonly assumed (e.g., Boer et al., 2013, Younas and Tang, 2013) that the difference between the potential and actual skill represents "room for model improvement"; however, as explained by Kumar et al. (2014), there is not necessarily a relationship between the potential and the actual skill of climate models, and assuming that there should be one amounts to expecting that the real-world data should behave identically to the model predictions.

The second term in the right hand side of equation (2) quantifies the conditional biases and is referred to as the slope reliability (SREL). The last term quantifies the unconditional biases and it is referred to as the standardized mean error (SME). 
Forecast verification using the skill score and its decompositions in equation (2) is a diagnostic tool that produces a more realistic quantification of the forecast skill compared to taking the correlation coefficient at face value. Moreover, the decomposition of the skill in different bias sources can provide model developers with feedback about strengths and weaknesses of their models. In general, unconditional biases (large SME) can easily be removed with bias-correction methods (Hashino et al. 2007). Conditional biases (large SREL), on the other hand, may require more sophisticated calibration. However, forecasts with low potential skill (PS) will have limited predictability, even if biases are eliminated.

To perform the skill verification of the NMME data, we tailor the PRISM and NMME data to cover the same months between January 1982 and December 2014. The verification is carried out for each model ensemble mean, region, and lead time following the above procedure, as also described in Bradley and Schwartz (2011). A separate skill verification is conducted on the eight-model ensemble mean, which is the mean forecast of all models (where one model already represents the arithmetic mean of its own ensemble members), for each region and lead time.

\subsection{Extreme event diagnosis}

The second part of the diagnosis is the assessment of each model's ability to predict extreme floods and droughts at the seasonal scale. To do this, we investigate the models' capacity to capture prolonged periods of extreme precipitation and temperature lasting several months. Eight extreme flood and drought events affecting different parts of the continental United States were selected based on their severity and duration. The event had to last at least one full month, and less than a year, so that we might evaluate its predictability for multiple lead times. The severity of the events was evaluated using the NOAA's Billion Dollar Weather and Climate Disasters Table of Events (https://www.ncdc.noaa.gov/billions/events). The chosen events include four floods (July-August 1993, January-March 1995, June-August 2008, and March 2010) and four droughts (June-August 1988, March-November 2002, March-August 2011, and May-August 2012). For the flood events, we focus on positive precipitation anomalies (high rainfall), and for the droughts, we observe positive temperature anomalies and negative precipitation anomalies (high temperature and lack of rainfall).

We first define the extent of each event based on the description given in the Billion Dollar Weather Table. The PRISM data are aggregated over the entire continental United States at the $1^{\circ} \times 1^{\circ}$ resolution to match the spatial resolution of the NMME data. At each 1-degree pixel and for the period of interest for a given event, we compute the standardized anomalies with respect to the mean and standard deviation computed over the 1983-2014 period (the years 1982 and 2015 are excluded systematically because not all models have a complete forecast for 1982, and 2015 forecast data were not yet available for all events at the time of the analysis). We then extract all the cells with standardized anomalies larger than 1 and smaller than -1 
(depending on whether we are considering excess temperature/precipitation or lack of rainfall). The resulting raster contains only the grid cells for that event which were "anomalously" high or low with respect to the 1983-2014 climatology. The boundaries of the event are tailored to the locations indicated in the Billion Dollar Weather Table (Figure 2). We then average all the pixels within this identified region for the months characterizing each event (e.g., total rainfall for the June-August 2008, for each year between 1983 and 2014) and compute the "domain averaged" standardized anomalies. Confidence intervals are computed around the anomaly for the given extreme event using the approach described in Stedinger et al.

234 (1993, section 18.4.2).

Last, we use a similar procedure to calculate the corresponding NMME anomalies within the defined region.

236 One mean (spatially-averaged) model forecast is extracted for the entire region for the selected months

237 between 1983 and 2014, for each lead time. To obtain a seasonal forecast value we compute the sum of

238 forecasts initialized ahead of the entire season. Thus, for an event such as the June-August 2008 flood, the seasonal forecast initialized in June 2008 (just before the event) is calculated as the sum of the 0.5-, the 1.5, and the 2.5-month lead forecasts initialized in June. If we initialize the forecast one month earlier, in May, the forecast can be calculated as the sum of the 1.5-, the 2.5- and the 3.5-month lead forecasts initialized that month. The forecast is calculated for increasingly long initialization times by going back in monthly time steps, as far the available lead times will allow. The resulting seasonal forecasts are then computed as anomalies, to allow a direct comparison with the average PRISM climatological anomaly for the event.

\section{Results}

\subsection{Regional temperature and precipitation forecast skill}

\subsubsection{Temperature}

The potential skill of the eight-model ensemble mean, as measured by the squared correlation coefficient between model forecasts and PRISM observations, ranges between 0 and 0.6 (Figure 3a). We find that the highest skill is displayed at the shortest lead time (0.5-month lead) and declines rapidly thereafter, so most regions and months display a skill smaller than 0.1 by the 1.5 -month lead time (Figure 3a). The Northwest and Southwest tend to show better skill than the other regions at longer lead times, e.g., over the JanuaryMarch and June-July periods respectively, possibly because of the good predictability of temperature anomalies arising from ENSO conditions during the same months (see e.g., Wolter and Timlin 2011, and mapping of the likelihood of seasonal extremes by the NOAA/ESRL Physical Science Division at

256 http://www.esrl.noaa.gov/psd/enso/climaterisks/). Other regions such as the Midwest show almost no skill 257 beyond the shortest lead time, possibly because of the weaker relationship with ENSO states. 
Overall, the ensemble mean displays better ability than any of the individual models, with potential skill maxima that exceed that of any single model (see for example April temperatures in the Midwest at the 0.5lead time, Figures 3-4), in agreement with other assessments of NMME model skill (Infanti and Kirtman 2014, Kirtman et al. 2014). There is not one model that clearly outperforms any of the others, although CCSM4, CanCM3, CanCM4, GEOS5 and CFSv2 do display better skill than CCSM3, GFDL2.1, and FLORb01 (Figure 4). The same seasonal and regional patterns can be seen for the individual models as for the ensemble mean, with a clear peak in potential skill in the Southwestern region in the summer months (CCSM4, CanCM4).

The actual skill score is relatively low for all models and is mainly driven by the large unconditional biases (SME) in the models. The influence of the unconditional biases on the skill score is clearly detectable in the mirror-image pattern between the two (Figures 3-4). Dark blue colors indicating low skill score are reflected by the dark red colors indicating a high unconditional bias. Overall, the skill score tends to be higher at the shortest lead times. For the ensemble mean, it can be quite high in specific regions such as the Midwest at the 0.5-month lead time during the cold season. Individual models, however, exhibit low skill scores over most regions and months, with values reaching below -10 most of the time (see Supplementary Materials pp.26-29 for additional graphs indicating skill decomposition for the eight-model ensemble mean and for each individual model).

The unconditional biases display strong seasonal variability: they tend to be the lowest (white) in most regions in the winter/spring months, and tend to increase dramatically (red) in the summer. By contrast, the Northwest and Southwest exhibit systematically higher biases in the winter and spring (particularly in the model ensemble). Therefore, as a result of this seasonality (e.g., better characterization of initial land surface conditions in the cold seasons), the unconditional biases also show some lead-dependence: during the summer months, they are the highest at the shortest leads (dark red), and decrease progressively with lead time (as is visible in the case of CanCM4/CanCM3, and to a lesser extent CFSv2). These seasonal fluctuations have a notable influence on the overall skill score, and suggest that forecasts made in the summer months could generally be improved by eliminating the unconditional biases.

The conditional biases (SREL) tend to range between 0 and 1, and are thus about an order of magnitude lower than the unconditional biases, which are mostly between about 0 and 10. Conditional biases are typically very low during most of the year (Figure 3), and they do not vary notably by lead time for most of the models (Figure 4). One visible exception is the case of CanCM3 and CanCM4, which exhibit a 'stepped' appearance, so the conditional biases increase (become redder) as lead time increases. These 
later months (see CanCM4 conditional biases in the Southwest, for an example). Some of the other models, like GFDL2.1 and GEOS5, also reveal some seasonality in their conditional biases.

\subsubsection{Precipitation}

Precipitation forecasts generally have lower potential skill than temperature (Figure 3B), as expected and found in other studies, due to the greater variability in rainfall patterns (e.g., Infanti and Kirtman 2015). The eight-model ensemble mean has better skill than each of the individual models (Figure 3B vs Figure 5), and the regions with the highest eight-model potential skill reflect the ability of the most skillful models (e.g., CCSM4, CFSv2 in the Southeast). However, all of the individual models display relatively low potential skill, especially after the 0.5-month lead (consistent with results found by Mo and Lyon (2015)), and little spatial variation on the regional scale (Figure 5). The models with the poorest forecasting ability (e.g., CCSM3 and FLORb01) do not even display potential skill at the 0.5-month lead. Other models (e.g., CCSM4, the Canadian models, GEOS5 and CFSv2) display some skill at longer lead times, but only for specific months, such as July in the Northwest (for CCSM4, GFDL2.1, CanCM4, and FLORB01), or May in the Southwest (e.g., CanCM4, GEOS5).

Similarly to temperature, the skill score for precipitation is mainly driven by unconditional biases in the models: the positive unconditional biases (red patterns) are mirrored by the negative skill score (blue patterns). Overall, however, the skill score for precipitation displays slightly less extreme (positive and negative) values than for temperature. This 'subdued' behavior could be caused by the greater variability in precipitation rates (i.e., lower agreement among forecast patterns) in space and time, for different months, lead times, and models. In other words, because of the small spatial scales of precipitation forecasts (compared to temperature), better results might be achieved by focusing on smaller spatial regions than the seven broad regions used here.

Interestingly, the seasonality of model skill also varies regionally for precipitation, but is different from the regional patterns for temperature. For the Northwest, Southwest, Great Plains North, Midwest, and Northeast regions, the highest unconditional biases in the precipitation forecasts tend to occur more frequently (lower skill) in the winter months (Figure 3B). The Great Plains South and Southeast regions, on the contrary, display lower unconditional biases (higher skill) in the winter months. This finding is consistent with that of Infanti and Kirtman (2014) for the southeastern United States, and suggests that improved model skill in the winter months may well be related to the influence of ENSO (e.g., Mo and Lyon, 2015, Roundy et al., 2015). In some regions, the unconditional biases tend to increase as the lead time of the forecast increases, so the color maps become progressively redder towards the right side of the plots (e.g., the Northwest region for CanCM3, FLORb01, or CFSv2) (Figure 5). Elsewhere the biases 
decrease with increasing lead time (e.g., Great Plains South, FLORb01). All eight models display considerable biases, but CCSM3 displays the largest biases, specifically in the Great Plains North region.

The conditional biases are again much lower than the unconditional biases, and much more variable, displaying little regularity by month or by lead time. Some months display slightly higher conditional biases (e.g., April or July), but such patterns are infrequent. CCSM3 and CCSM4 have the largest conditional biases (red), followed by GFDL2.1, while the Canadian models, GEOS5 and CFSv2 tend to show lower conditional biases. Regionally, there seem to be slightly greater biases in the Southwest and Great Plains North.

\subsection{Individual extreme events}

\subsubsection{Floods}

We evaluate the skill of the eight NMME models in predicting four flood events (the 1993 July-August flood, the 1995 January-March flood, the 2008 June-August flood, and March 2010) by comparing the observed climatology (Figure 2, A-D) to the model precipitation forecasts (positive anomalies). As a caveat, it should first be conceded that we do not expect the models to reflect the observed historical precipitation anomalies perfectly over such broad spatial scales, even in the best-case scenarios, because of convection patterns that occur at local scales (and that cannot be captured in the same way as extreme temperature anomalies, which exhibit more spatially-consistent patterns). Overall, results indicate that the four flood events were relatively poorly predicted by all eight models (Figure 6, A-D). The 1993 Midwest flooding stands out as the least poorly forecasted, since all models with the exception of CCSM3 predicted positive anomalies. CanCM4, CCSM4, FLORb01, CFSv2 and CanCM3 all forecasted anomalies that were more than 2 times greater than their own average seasonal value (Figure 6A). However, the actual historical anomaly was much greater than any of the predicted values, at 3.80. Generally speaking, skillful predictions tend to occur in regions that have strong air-sea coupling, so the initial condition of the atmosphere plays an important role in the forecast for several months (Materia et al., 2014). In the case of the 1993 flood, it is likely that the good skill of the models is due to the strength of the El Niño, which displaced the storm track over the central United States, with atmospheric rivers transporting large amounts of moisture from the Gulf of Mexico over the Mississippi River basin (Trenberth and Guillemot, 1996; Lavers and Villarini, 2013). The El Niño conditions also likely explain why the ability of the eight models to predict the 1993 flood visibly decreased here with initialization time (i.e., the further ahead of the event, the less able the models were to forecast the high rainfall).

The other three events were relatively less well forecast, although CFSv2 performed better than all other models in 2008 (Figure 6C), as did FLORb01 in 2010 at the shortest lead time (Figure 6D). The observed 
event anomalies (PRISM data) were of 2.34, 2.55, and 2.78 while the model forecasts, at best, attained 1.8 (GFDL2.1 - 1995 flood), 1.5 (CFSv2 - 2008 flood) and 2.3 (CFSv2 - 2010 flood), but somewhat fortuitously, since some of the highest anomalies were predicted many months ahead of the actual events. In fact, for all three of these flood events (Figure 6B-D), the eight-model ensemble mean is near zero, or below zero, and half of the individual model forecasts predicted a "drier-than-average" season. Figure 6BD indicates that most models fluctuate between positive and negative anomalies, and in 2008 were wrong, predicting a drier-than-average season overall; as for the other flood events, the predicted anomalies were as low as -1.5 (1995 flood - GEOS5), -2.5 (2008 flood - CanCM4), and -2.4 (CFSv2 - 2010 flood). Thus, no model consistently outperformed any of the others, and no single model was reliable in terms of consistently predicting these three flood events (Figure 6B-D).

\subsubsection{Droughts}

Droughts tend to develop more slowly than floods, since it can take between five and eight months for the water deficit to drop beneath a certain threshold and begin a drought (Mo, 2011). Hence, skillful intraseasonal to interannual forecasts may prove particularly vital ahead of major drought events. Additionally, droughts also tend to be more predictable than floods because of the influence of the Pacific Decadal Oscillation (PDO) and the Atlantic Multi-decadal Oscillation (AMO) (McCabe et al. 2004) and the effects of land surface/atmosphere coupling (e.g., Koster et al., 2006, Seneviratne et al., 2010). Thus, droughts that are strongly influenced by initial conditions tend to be well-forecast (Roundy and Wood, 372 2014).

373 Here we evaluate the ability of NMME models to predict droughts as high temperature anomalies (excess heat Figure 2, E-H) on the one hand, and low precipitation anomalies (lack of rainfall, Figure 2, I-L) on the other, in comparison with the observed climatology (red shades for excess temperature, blue shades for lack of rain). The comparison between temperature and precipitation predictions for drought events also allows us to determine whether the NMME models are more accurate in predicting excess heat or deficient rainfall, and to what extent temperature actually contributed to drought severity for each of these events. For instance, in the case of the 2014 California drought, it was shown that while low precipitation was the main driver of the event, temperature contributed strongly to intensifying the drought (Shukla et al., 2015).

The comparison between observed extreme temperature and observed extreme precipitation anomalies reveals a relatively good overlap in spatial extents (Figure 2) with the exception of the 2002 MarchNovember drought, which was also the least predictable of the four droughts (only small isolated parts of the south-east and south-west United States were affected by the positive temperature anomaly, Figure 2F). During droughts, strong precipitation deficits and high heat anomalies tend to occur over the same regions, as was the case during the 1934, 1936, 2011 and 2012 events (Donat et al., 2016). The discrepancies 
between temperature and precipitation patterns tend to be relatively limited in space and are mainly caused by the noise associated with the precipitation signal; for instance, localized thunderstorms that occur in spring and summer may influence the rainfall anomalies computed for an entire season.

Of the four drought events, it appears that the 1988 drought was remarkably well predicted at the shortest initialization time by four models (GEOS5, CFSv2, CanCM3 and GFDL2.1) in terms of high temperature (Figure 6E). The first two of those models actually exceeded the observed anomaly (PRISM=2.1), with forecast values of 2.6 and 2.4. However, the skill of all models decreases rapidly with increasing lead time, indicating that they were unable to predict the event more than one month ahead of its actual occurrence. For the same event, the precipitation forecasts (lack of rainfall) were also relatively successful in June 1988 (anomaly values of -3.2 for GEOS5, -2.3 for CFSv2, -2.2 for GFDL2.1, in comparison with the observed -2.8) but the skill declined when predicted further ahead (Figure 6E). CCSM3 performed the least well among all models, while CanCM3 predicted the drought successfully both in terms of temperature and precipitation eight months ahead of the actual event (Figure 6E). Overall, the good predictability of the 1988 drought is likely a result of the strong La Niña conditions (e.g., Trenberth and Guillemot, 1996) that occurred in conjunction with a cooling phase of the PDO and the warming phase of the AMO (McCabe et al. 2004).

The other three droughts were relatively less well predicted. For 2002, the eight-model ensemble mean is close to climatology (anomaly value around 0), and in the month preceding the event, only GEOS5 predicted a positive temperature anomaly of 1.3 vs. 1.77 for the observed climatology, while half of the models actually predicted excess rainfall (Figure 6F). In 2011, the March-August forecasts were slightly more accurate, likely because the drought resulted from a strong La Niña (Seager and Hoerling, 2014) and the mean flow moisture divergence anomalies driven by the negative North Atlantic Oscillation of the previous winter (Seager et al. 2014). GFDL2.1 and FLORB01 both consistently predicted high positive temperature anomalies and low negative precipitation anomalies, even at the longer times before the event, and the eight-model ensemble mean correctly predicted positive/negative anomalies (Figure 6G). Last, the 2012 drought was relatively well predicted, with slightly better results for temperature than precipitation. However, contrary to model forecasts, Pacific sea surface temperature (SST) did not play a major role in the drought (Kumar et al. 2013, Hoerling et al. 2013), so the skillful prediction of the drought was in fact "fortuitous, due to the erroneous coupling with pan-Pacific SSTs" (Kam et al. 2014). CanCM3 and CanCM4 display good results, but they become less skillful as one approaches the beginning of the event (Figure $6 \mathrm{H})$. As suggested by Roundy and Wood (2014), the varying skill of drought forecasts among years implies that they are driven by different mechanisms; atmospheric and land initial conditions, SST and radiative forcing may have varying influences to strengthen/weaken the predictability of events (Jia et al. 2016). 
Overall, it is interesting to note that the precipitation and temperature forecasts are more similar than one might expect in terms of their ability to forecast the extreme events. In fact, comparing the positive temperature anomalies with the negative precipitation anomalies (Figure 6E-L) indicates that seasonal precipitation and temperature forecasts do tend to reflect one another to a certain extent. When the temperature forecast is skillful, the precipitation forecast tends to be also (e.g., GEOS5 and CanCM3 in 1988, or GFDL in 2011, Figure 6G). Likewise, the lack of skill is also mirrored for both temperature and precipitation (e.g., CCSM3 in 2011, Figure 6G).

Comparing our results with historical ENSO forecasts suggests that when the land surface/atmosphere interaction is well represented, events tend to be better predicted; hence, the lack of land surface/atmosphere coupling in 2002 may explain why the drought was poorly predicted and why there was little consistency between temperature and precipitation patterns. Therefore, as different models have different abilities depending on seasonality and lead times, strategic multi-model averaging procedures may help increase the forecasting skill of these extreme flood and drought events (e.g., Luo and Wood 2008, Bradley et al. 2015), especially in locations with strong antecedent ENSO signal (e.g., Yuan and Wood, 2013).

\section{Summary and conclusions}

By decomposing the skill score of the individual climate models into potential skill, unconditional and conditional biases, we have assessed the strengths and weaknesses of the eight GCM ensemble means and of the eight-model ensemble mean over a range of lead times and initialization months. Our findings provide a diagnostic tool that can give model developers feedback about strengths and weaknesses of their models, and help develop better model-averaging strategies.

The results can be summarized as follows:

1. The highest potential skill in temperature and precipitation forecasts is displayed at the shortest lead time ( 0.5 month) and declines rapidly thereafter. For both temperature and precipitation, the potential skill of the eight-model ensemble mean does tend to surpass the skill of the best model within the ensemble. However, there is room for more sophisticated model averaging approaches (i.e., weighting individual models based on their strengths and weaknesses) to improve the model ensemble skill. Overall, the skill score is quite low for all models. The eight-model ensemble displays positive values mostly in the shortest lead times, and there is not one model that clearly outperforms any of the others.

2. The biases in these eight models are predominantly unconditional (SME), with strong seasonaland lead-dependent biases driving the negative skill scores (which are likely dependent on the initialization conditions in different regions and seasons). For temperature, in most regions, the 
unconditional biases tend to be the lowest in the winter/spring months, and to increase in the summer (while the reverse is true in the Northwest and Southwest). For precipitation, the unconditional biases tend to be the lowest in the summer and fall (while the reverse is true in the

These findings highlight some of the strengths and weaknesses of the NMME models across all lead times, months, and for seven major regions of the United States. One of the remaining challenges is our ability to extend precipitation forecast skill beyond the shortest lead time, as is recognized in similar studies (Wood et al. 2015). The overall skill of the eight-model ensemble shows promise for multi-model averaging procedures (e.g., Luo et al 2007, Bradley et al. 2015) that might enable more skillful forecasts at longer lead times. Moreover, future studies should examine whether it is possible to utilize these precipitation and 485 


\section{Bibliography}

487 Becker, E., H. Van den Dool, and Q. Zhang (2014) Predictability and Forecast Skill in NMME. Journal of 488 Climate, 27(15), 5891-5906. http://doi.org/10.1175/JCLI-D-13-00597.1

489 Boer, G. J., V. V. Kharin, and W. J. Merryfield (2013) Decadal predictability and forecast skill. Climate Dynamics, 41(7-8), 1817-1833, http://doi.org/10.1007/s00382-013-1705-0

491 Bradley, A.A., and S.S. Schwartz (2011) Summary verification measures and their interpretation for

492 ensemble forecasts, Monthly Weather Review, 139(9), 3075-3089,

493 http://doi.org/10.1175/2010MWR3305.1

494 Bradley, A.A., M. Habib, and S.S. Schwartz (2015) Climate index weighting of ensemble streamflow 495 forecasts using a simple Bayesian approach. Water Resources Research, 51(9), 1-49. 496 http://doi.org/10.1002/2014WR016811

497 Delsole, T., J. Nattala, and M.K. Tippett (2014) Skill improvement from increased ensemble size and model 498 diversity, Geophysical Research Letters, 41(20), 7331-7342. http://doi.org/10.1002/2014GL060133

499 Daly, C., W.P. Gibson, G.H. Taylor, G.L. Johnson, and P. Pasteris (2002) A knowledge-based approach to 500 the statistical mapping of climate, Climate Research, 22(9), 99-113

501 DelSole, T., and M.K. Tippett, Comparing Forecast Skill (2014) Monthly Weather Review, 142(12), 4658502 4678. http://doi.org/10.1175/MWR-D-14-00045.1

503 Delworth, T.L., A.J. Broccoli, A. Rosati, R.J. Stouffer, V. Balaji, J.A. Beesley, W.F. Coke, K.W. Dixon, J. 504 Dunne, K.A. Dunne, and J.W. Durachta (2006) GFDL's CM2 global coupled climate models. Part I: 505 Formulation and simulation characteristics. Journal of Climate, 19(5), 643-674. 506 http://doi.org/10.1175/JCLI3629.1

507 Donat, M.G., A.D. King, J.T. Overpeck, L.V. Alexander, I. Durre, and D.J. Karoly (2016) Extraordinary 508 heat during the 1930s US Dust Bowl and associated large-scale conditions. Climate Dynamics 46(1-2), 509 413-426 http://doi.org/10.1007/s00382-015-2590-5

510 Hagedorn, R., F.J. Doblas-Reyes, and T.N. Palmer (2005) The rationale behind the success of multi-model 511 ensembles in seasonal forecasting-I. Basic concept, Tellus A, 57(3), 219-233, 512 http://doi.org/10.1111/j.1600-0870.2005.00103.x

513 Hashino, T., A.A. Bradley, and S.S. Schwartz (2007) Evaluation of bias-correction methods for ensemble 514 streamflow volume forecasts, Hydrology and Earth System Sciences Discussions, 3(2), 561-594 
Hijmans, R. (2015) raster: Geographic Data Analysis and Modeling. R package version 2.4-18. http://CRAN.R-project.org/package=raster

Hoerling M., J. Eischeid, A. Kumar, R. Leung, A. Mariotti, K. Mo, S. Schubert and R. Seagar (2013) Causes and predictability of the 2012 Great Plains drought. Bulletin of the American Meteorological Society, 95(2), 269-282. http://doi.org/10.1175/BAMS-D-13-00055.1

Infanti, J. M., and B.P. Kirtman (2014) Southeastern U.S. Rainfall Prediction in the North American MultiModel Ensemble. Journal of Hydrometeorology, 15(2), 529-550. http://dx.doi.org/10.1175/JHM-D-13072.1

Jia, L., X. Yang, G.A. Vecchi, R.G. Gudgel, T.L. Delworth, A. Rosati, W.F. Stern, A.T. Wittenberg, L. Krishnamurthy, S. Zhang, R. Msadek, S. Kapnick, S. Underwood, Fanrong Zeng, Whit G. Anderson, V. Balaji, and K. Dixon (2015) Improved seasonal prediction of temperature and precipitation over land in a high-resolution GFDL climate model. Journal of Climate, 28(5), 2044-2062. http://dx.doi.org/10.1175/JCLI-D-14-00112.1

Jia, L., G.A. Vecchi, X. Yang, R.G. Gudgel, T.L. Delworth, W.F. Stern, K. Paffendorf, S.D. Underwood, and F. Zeng (2016). The Roles of Radiative Forcing, Sea Surface Temperatures, and Atmospheric and Land Initial Conditions in U.S. Summer Warming Episodes. Journal of Climate, 29(11), 4121-4135. http://doi.org/10.1175/JCLI-D-15-0471.1

Kam, J., J. Sheffield, X. Yuan, and E.F. Wood (2014) Did a skillful prediction of sea surface temperatures help or hinder forecasting of the 2012 Midwestern US drought? Environmental Research Letters, 9(3), 19. http://doi.org/10.1088/1748-9326/9/3/034005

Karl, T.R., J.M. Melillo, and T.C. Peterson, Eds. (2009) Global Climate Change Impacts in the United States. Cambridge University Press, 189 pp.

Kirtman, B.P., and D. Min (2009) Multimodel ensemble ENSO prediction with CCSM and CFS. Monthly Weather Review, 137(9), 2908-2930. http://dx.doi.org/10.1175/2009MWR2672.1

Kirtman, B.P., Du. Min, J.M. Infanti, J.L. Kinter, III, D.A. Paolino, Q. Zhang, H. van den Dool, S. Saha, M. Pena Mendez, E. Becker, P. Peng, P. Tripp, J. Huang, D.G. DeWitt, M.K. Tippett, A.G. Barnston, S. Li, A. Rosati, S.D. Schubert, M. Rienecker, M. Suarez, Z.E. Li, J. Marshak, Y.-K. Lim, J. Tribbia, K. Pegion, W.J. Merryfield, B. Denis, and E.F. Wood (2014) The North American Multimodel Ensemble: Phase-1 Seasonal-to-Interannual Prediction; Phase-2 toward Developing Intraseasonal Prediction, Bulletin of the American Meteorological Society, 95(4), 585-601. http://doi.org/10.1175/BAMS-D-12-00050.1 
Koster, R.D., Y.C. Sud, Z. Guo, P.A. Dirmeyer, G. Bonan, K.W. Oleson, E. Chan, D. Verseghy, P. Cox, H. Davies, and E. Kowalczyk (2006) GLACE: The Global Land- Atmosphere Coupling Experiment. Part I: Overview. Journal of Hydrometeology., 7(4), 590-610, http://doi.org/10.1175/JHM510.1.

Kumar, A., P. Peng, and M. Chen (2014) Is There a Relationship between Potential and Actual Skill? Monthly Weather Review, 142(6), 2220-2227. http://doi.org/10.1175/MWR-D-13-00287.1

Kunkel, K. E., T. R. Karl, H. Brooks, J. Kossin, J. H. Lawrimore, D. Arndt, L. Bosart, D. Changnon, S.L. Cutter, N. Doesken, K. Emanuel, P. Y. Groisman, R.W. Katz, T. Knutson, J. O'brien, C.J. Paciorek, T.C. Peterson, K. Redmond, D. Robinson, J. Trapp, R. Vose, S. Weaver, M. Wehner, K. Wolter, and D. Wuebbles (2013) Monitoring and understanding trends in extreme storms: State of knowledge. Bulletin of the American Meteorological Society, 94(4), 499-514. http://doi.org/10.1175/BAMS-D-11-00262.1

Lavers, D.A., and G. Villarini (2013) Atmospheric rivers and flooding over the central United States. Journal of Climate, 26(20): 7829-7836.

Lawrence, D.M., K.W. Oleson, M.G. Flanner, C.G. Fletcher, P.J. Lawrence, S. Levis, S.C. Swenson, and G.B. Bonan (2012) The CCSM4 land simulation, 1850-2005: Assessment of surface climate and new capabilities. Journal of Climate 25(7) 2240-2260

Luo, L.F., E.F. Wood, and M. Pan (2007) Bayesian merging of multiple climate model forecasts for seasonal hydrological predictions, Journal of Geophysical Research-Atmospheres, 112(D10), http://doi.org/10.1029/2006JD007655

Luo, L. F., and E. F. Wood (2008) Use of Bayesian merging techniques in a multimodel seasonal hydrologic ensemble prediction system for the eastern United States, Journal of Hydrometeorology, 9(5), 866-884.

Ma, F., A. Ye, X. Deng, Z. Zhou, X. Liu, Q. Duan, J. Xu, C. Miao, Z. Di, and W. Gong (2015a) Evaluating the skill of NMME seasonal precipitation ensemble predictions for 17 hydroclimatic regions in continental China. International Journal of Climatology, 36(1),132-144. http://doi.org/10.1002/joc.4333

Ma, F., X. Yuan, and A. Ye (2015b) Seasonal drought predictability and forecast skill over China. Journal of Geophysical Research: Atmospheres, 120(16), 8264-8275. http://doi.org/10.1002/2015JD023185

McCabe G.J, M.A. Palecki, and J.L. Betancourt (2004). Pacific and Atlantic Ocean influences on multidecadal drought frequency in the United States. Proceedings of the National Academy of Sciences. 101(12), 4136-41 http://doi.org/10.1073/pnas.0306738101

Materia S., A. Borrelli, A. Bellucci et al (2014). Impact of atmosphere and land surface initial conditions on seasonal forecasts of global surface temperature. Journal of Climate. 27(24), 9253-9271. http://dx.doi.org/10.1175/JCLI-D-14-00163.1 
576 Merryfield, W.J., W.-S. Lee, G. J. Boer, V.V. Kharin, J.F. Scinocca, G.M. Flato, R.S. Ajayamohan, J.C.

577 Fyfe, Y. Tang, and S. Polavarapu (2013) The Canadian seasonal to interannual prediction system. Part I:

578 Models and initialization. Monthly Weather Review 141(8), 2910-2945. http://doi.org/10.1175/MWR-D-

579 12-00216.1

580 Misra, V., and H. Li (2014) The seasonal climate predictability of the Atlantic Warm Pool and its 581 teleconnections, Geophysical Research Letters, 41(2), 661-666, http://doi.org/10.1002/2013GL058740

582 Mo, K. (2011) Drought onset and recovery over the United States, Journal of Geophysical Research, 583 116(D20), http://doi.org/10.1029/2011JD016168

584 Mo, K.C., and D.P. Lettenmaier (2014) Hydrologic prediction over the conterminous United States using 585 the National Multi-Model Ensemble, Journal of Hydrometeorology, 15(4), 1457-1472. 586 http://dx.doi.org/10.1175/JHM-D-13-0197.1

587 Mo, K. C., and B. Lyon (2015) Global Meteorological Drought Prediction using the North American Multi588 Model Ensemble. Journal of Hydrometeorology, 16(3), 1409-1424 http://doi.org/10.1175/JHM-D-14$589 \quad 0192.1$

590 Molod, A., L. Takacs, M. Suarez, J. Bacmeister, I.-S. Song, and A. Eichmann (2012) The GEOS-5 591 atmospheric general circulation model: mean climate and development from MERRA to Fortuna. Technical 592 Report Series on Global Model Data Assimilation, vol 28. NASA Goddard Space Flight Cent., Greenbelt, $593 \mathrm{p} 175$.

594 Murphy, A.H., and R.L. Winkler (1992) Diagnostic verification of probability forecasts, International 595 Journal of Forecasting, 7(4), 435-455, http://doi.org/10.1016/0169-2070(92)90028-8

596 National Research Council (US) Committee on Assessment of Intraseasonal to Interannual Climate 597 Prediction and Predictability (2010) Assessment of Intraseasonal to Interannual Climate Prediction and 598 Predictability. National Academies Press.

599 Pierce, D. (2014) ncdf4: Interface to Unidata netCDF (version 4 or earlier) format data files. R package 600 version 1.12. http://dwpierce.com/software

601 Roundy, J.K., E. Wood (2015). The Attribution of Land-Atmosphere Interactions on the Seasonal 602 Predictability of Drought, Journal of Hydrometeorology $16.2 \quad$ (2015): 793-810. 603 http://dx.doi.org/10.1175/JHM-D-14-0121.1

604 Roundy, J.K., X. Yuan, J. Schaake, E.F. Wood (2015) A Framework for Diagnosing Seasonal Prediction 605 through Canonical Event Analysis. Monthly Weather Review, 143(6), 2404-2418. 606 http://doi.org/10.1175/MWR-D-14-00190.1 
Saha, S., S. Moorthi, X. Wu, J. Wang, S. Nadiga, P. Tripp, D. Behringer, Y.-T. Hou, H.-Y. Chuang, M. Iredell, M. Ek, J. Meng, R. Yang, M. Peña Mendez, H. van den Dool, Q. Zhang, W. Wang, M. Chen, and E. Becker (2014) The NCEP Climate Forecast System Version 2. Journal of Climate, 27(6), 2185-2208. http://dx.doi.org/10.1175/JCLI-D-12-00823.1

Seager, R., L. Goddard, J. Nakamura, N. Henderson, D.E. Lee. (2014). Dynamical Causes of the 2010/11 Texas-Northern Mexico Drought. Journal of Hydrometeorology, 15(1), 39-68. http://doi.org/10.1175/JHM-D-13-024.1

Seager, R., M. Hoerling (2014). Atmosphere and ocean origins of North American droughts. Journal of Climate, 27(12), 4581-4606. http://doi.org/10.1175/JCLI-D-13-00329.1

Seneviratne, T.C., E.L. Davin, M. Hirschi, E.B. Jaeger, I. Lehner, B, Orlowsky, A.J. Teuling (2010). Investigating soil moisture-climate interactions in a changing climate: A review. Earth-Science Reviews $99(3), 125-161$

Shukla, S., M. Safeeq, A. AghaKouchak, K. Guan, C. Funk (2015) Temperature impacts on the water year 2014 drought in California, Geophysical Research Letters, 42(11), 4384-4393, http://dx.doi.org/10.1002/2015GL063666

Stedinger, J.R, R.M, Vogel, and E. Foufoula-Georgiou (1993) Chapter 18, Frequency analysis of extreme events, Handbook of Hydrology. Edited by D.R. Maidment, McGrawHill Book Company, New York.

Thober, S., R. Kumar, J. Sheffield, J., Mai, D. Schäfer, and L. Samaniego (2015) Seasonal Soil Moisture Drought Prediction over Europe using the North American Multi-Model Ensemble (NMME). Journal of Hydrometeorology, 16(6), 2329-2344. http://doi.org/10.1175/JHM-D-15-0053.1

Tian, D., C.J. Martinez, W.D. Graham, and S. Hwang (2014) Statistical Downscaling Multimodel Forecasts for Seasonal Precipitation and Surface Temperature over the Southeastern United States. Journal of Climate, 27(22), 8384-8411. http://doi.org/10.1175/JCLI-D-13-00481.1

Trenberth, K.E., \& Guillemot, C.J. (1996). Physical processes involved in the 1988 drought and 1993 floods in North America. Journal of Climate. 9(6), 1288-1298 http://doi.org/10.1175/15200442(1996)009<1288:PPIITD>2.0.CO;2

Vecchi, G.A., T. Delworth, R. Gudgel, S. Kapnick, A. Rosati, A., Wittenberg, F. Zeng, W. Anderson, V. Balaji, K. Dixon, L. Jia, H.-S. Kim, L. Krishnamurthy, R. Msadek, W.F. Stern, S.D. Underwood, G. Villarini, X. Yang, S. Zhang (2014) On the Seasonal Forecasting of Regional Tropical Cyclone Activity. Journal of Climate, 27(21) 7994-8016. http://doi.org/10.1175/JCLI-D-14-00158.1 
637 Vernieres, G., M.M. Rienecker, R. Kovach, and C. L. Keppenne (2012) The GEOS-iODAS: Description 638 and evaluation. GEOS5 Technical Report GEOS5/TM-2012-104606, Vol 30, 61 pp.

639 Wang, H., Evaluation of monthly precipitation forecasting skill of the National Multi-model Ensemble in 640 the summer season (2014) Hydrological Processes, 28(15), 4472-4486. http://doi.org/10.1002/hyp.9957

641 Wolter, K., M.S. Timlin (2011). El Nino/Southern Oscillation behaviour since 1871 as diagnosed in an 642 extended multivariate ENSO index (MEI.ext). International Journal of Climatology, 31(7), 1074-1087. 643 http://doi.org/10.1002/joc.2336

644 Wood, E F., S.D. Schubert, A.W. Wood, C.D. Peters-Lidard, K. C. Mo, A. Mariotti, and R.S. Pulwarty 645 (2015) Prospects for Advancing Drought Understanding, Monitoring, and Prediction. Journal of 646 Hydrometeorology, 16(4), 1636-1657. http://doi.org/10.1175/JHM-D-14-0164.1

647 Younas, W., and Y. Tang (2013) PNA predictability at various time scales. Journal of Climate, 26(22), 648 9090-9114, http://doi.org/10.1175/ JCLI-D-12-00609.1

649 Yuan, X., and E. F. Wood (2013) Multimodel seasonal forecasting of global drought onset. Geophysical 650 Research Letters, 40(18), 4900-4905. http://doi.org/10.1002/grl.50949

651 Zhang, S., M.J. Harrison, A. Rosati, and A. Wittenberg (2007) System design and evaluation of coupled 652 ensemble data assimilation for global oceanic climate studies. Monthly Weather Review, 135(10), 3541653 3564, http://doi.org/10.1175/MWR3466.1 
Table 1: Summary of the characteristics of the eight NMME models. The available period does not reflect the presence of gaps in the forecasts. The number of ensemble members indicates the largest number of members per GCM and is not reflective of missing data for one or more members. The 0.5 -lead time is the shortest available lead time and refers to the forecast for a month issued at the beginning of the month

658 itself (e.g., the 0.5 lead time forecast for January 2000 is issued at the beginning of January 2000).

\begin{tabular}{|c|c|c|c|c|c|c|}
\hline Model name & Modeling Center & $\begin{array}{l}\text { Available } \\
\text { Period }\end{array}$ & $\begin{array}{l}\text { Ensemble } \\
\text { Size }\end{array}$ & $\begin{array}{l}\text { Lead Times } \\
\text { (months) }\end{array}$ & Reference & Retrieved from \\
\hline \multicolumn{7}{|l|}{ PHASE I models } \\
\hline $\begin{array}{l}\text { CCSM3 } \\
\text { (Community } \\
\text { Climate System } \\
\text { Model, version 3) }\end{array}$ & $\begin{array}{l}\text { National Center for } \\
\text { Atmospheric Research } \\
\text { (NCAR); Center for Ocean-- } \\
\text { Land-Atmosphere Studies } \\
\text { (COLA); Rosenstiel School } \\
\text { for Marine and Atmospheric } \\
\text { Science, University of Miami } \\
\text { (RSMAS) }\end{array}$ & $\begin{array}{l}1982 \text { - } \\
\text { Present }\end{array}$ & 6 & $0.5-11.5$ & $\begin{array}{l}\text { Kirtman and } \\
\text { Min } 2009\end{array}$ & $\begin{array}{l}\text { http://iridl.ldeo.colu } \\
\text { mbia.edu/SOURCES } \\
\text { /.Models/.NMME/.C } \\
\text { OLA-RSMAS- } \\
\text { CCSM3/ }\end{array}$ \\
\hline $\begin{array}{l}\text { CCSM4 } \\
\text { (Community } \\
\text { Climate System } \\
\text { Model, version } 4 \text { - } \\
\text { subset of CESM1) }\end{array}$ & $\begin{array}{l}\text { NCAR / COLA / RSMAS (as } \\
\text { above) }\end{array}$ & $\begin{array}{l}1982- \\
\text { Present }\end{array}$ & 10 & $0.5-11.5$ & $\begin{array}{l}\text { Lawrence et } \\
\text { al. } 2012\end{array}$ & $\begin{array}{l}\text { http://iridl.ldeo.colu } \\
\text { mbia.edu/SOURCES } \\
\text { /.Models/.NMME/.C } \\
\text { OLA-RSMAS- } \\
\text { CCSM4/ }\end{array}$ \\
\hline \multicolumn{7}{|l|}{ PHASE II models } \\
\hline $\begin{array}{l}\text { CanCM3 } \\
\left(3^{\text {rd }} \text { Generation }\right. \\
\text { Canadian Coupled } \\
\text { Global Climate } \\
\text { Model })\end{array}$ & $\begin{array}{l}\text { Environment Canada's } \\
\text { Meteorological Service } \\
\text { of Canada - Canadian } \\
\text { Meteorological Centre (CMC) }\end{array}$ & $\begin{array}{l}1981- \\
\text { Present }\end{array}$ & 10 & $0.5-11.5$ & $\begin{array}{l}\text { Merryfield et } \\
\text { al. } 2013\end{array}$ & $\begin{array}{l}\text { http://iridl.ldeo.colu } \\
\text { mbia.edu/SOURCES } \\
\text { /.Models/.NMME/.C } \\
\text { MC1-CanCM3/ }\end{array}$ \\
\hline $\begin{array}{l}\text { CanCM4 } \\
\left(4^{\text {th }} \text { Generation }\right. \\
\text { Canadian Coupled } \\
\text { Global Climate } \\
\text { Model })\end{array}$ & CMC (as above) & $\begin{array}{l}1981- \\
\text { Present }\end{array}$ & 10 & $0.5-11.5$ & $\begin{array}{l}\text { Merryfield et } \\
\text { al. } 2013\end{array}$ & $\begin{array}{l}\text { http://iridl.ldeo.colu } \\
\text { mbia.edu/SOURCES } \\
\text { /.Models/.NMME/.C } \\
\text { MC2-CanCM4/ }\end{array}$ \\
\hline $\begin{array}{l}\text { CCSM4 } \\
\text { (Community } \\
\text { Climate System } \\
\text { Model, version 4- } \\
\text { subset of CESM1) } \\
\end{array}$ & $\begin{array}{l}\text { NCAR / COLA / RSMAS (as } \\
\text { above) }\end{array}$ & $\begin{array}{l}1982- \\
\text { Present }\end{array}$ & 10 & $0.5-11.5$ & $\begin{array}{l}\text { Lawrence et } \\
\text { al. } 2012\end{array}$ & $\begin{array}{l}\text { http://iridl.ldeo.colu } \\
\text { mbia.edu/SOURCES } \\
\text { /.Models/.NMME/.C } \\
\text { OLA-RSMAS- } \\
\text { CCSM4/ } \\
\end{array}$ \\
\hline $\begin{array}{l}\text { CFSv2 } \\
\text { (operational } \\
\text { Climate Forecast } \\
\text { System version 2) } \\
\end{array}$ & $\begin{array}{l}\text { NOAA's National Centers for } \\
\text { Environmental Prediction } \\
\text { (NCEP) }\end{array}$ & $\begin{array}{l}1982- \\
\text { Present }\end{array}$ & $\begin{array}{l}28 \text { (24 used / } \\
4 \text { are } \\
\text { incomplete })\end{array}$ & $0.5-9.5$ & $\begin{array}{l}\text { Saha et al. } \\
2014\end{array}$ & $\begin{array}{l}\text { http://iridl.ldeo.colu } \\
\text { mbia.edu/SOURCES } \\
\text { /.Models/.NMME/.N } \\
\text { CEP-CFSv2/ }\end{array}$ \\
\hline $\begin{array}{l}\text { GEOS5 } \\
\text { (Goddard Earth } \\
\text { Observing System } \\
\text { Model, version 5) }\end{array}$ & $\begin{array}{l}\text { National Aeronautics and } \\
\text { Space Administration } \\
\text { (NASA)'s Global Modeling } \\
\text { and Assimilation Office } \\
\text { (GMAO) }\end{array}$ & $\begin{array}{l}1981 \text { - } \\
\text { Present }\end{array}$ & 12 & $0.5-8.5$ & $\begin{array}{l}\text { Vernieres et } \\
\text { al. 2012; } \\
\text { Molod et al. } \\
\quad 2012\end{array}$ & $\begin{array}{l}\text { http://iridl.ldeo.colu } \\
\text { mbia.edu/SOURCES } \\
\text { /.Models/.NMME/.N } \\
\text { ASA-GMAO- } \\
\text { 062012/ }\end{array}$ \\
\hline $\begin{array}{l}\text { GFDL2.1 } \\
\text { (Climate Model, } \\
\text { version 2.1) }\end{array}$ & $\begin{array}{l}\text { National Oceanic and } \\
\text { Atmospheric Administration } \\
\text { (NOAA)'s Geophysical Fluid } \\
\text { Dynamics Laboratory } \\
\text { (GFDL) }\end{array}$ & $\begin{array}{l}1982- \\
\text { Present }\end{array}$ & 10 & $0.5-11.5$ & $\begin{array}{l}\text { Zhang et al. } \\
\text { 2007; } \\
\text { Delworth et } \\
\text { al. } 2006\end{array}$ & $\begin{array}{l}\text { http://iridl.ldeo.colu } \\
\text { mbia.edu/SOURCES } \\
\text { /.Models/.NMME/.G } \\
\text { FDL-CM2p1-aer04/ }\end{array}$ \\
\hline $\begin{array}{l}\text { FLORb01 } \\
\text { (Climate Model } \\
\text { version 2.5) }\end{array}$ & NOAA's GFDL (as above) & $\begin{array}{l}1982- \\
\text { Present }\end{array}$ & 12 & $0.5-11.5$ & $\begin{array}{l}\text { Vecchi et al. } \\
2014\end{array}$ & $\begin{array}{l}\text { http://iridl.ldeo.colu } \\
\text { mbia.edu/SOURCES } \\
\text { /.Models/.NMME/.G } \\
\text { FDL-CM2p5-FLOR- } \\
\text { B01 }\end{array}$ \\
\hline
\end{tabular}




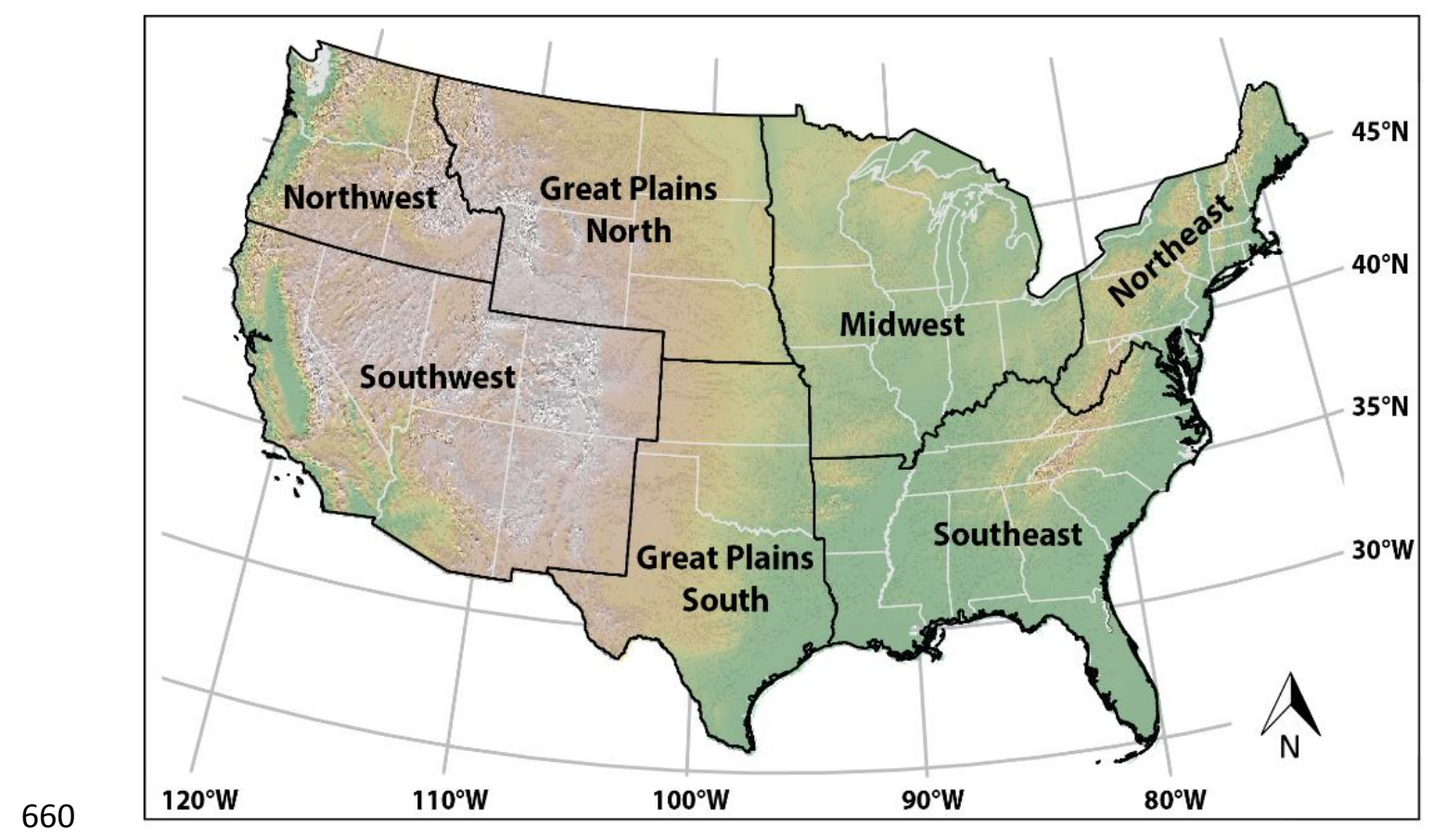

661 Figure 1. Location of the seven regions across the continental United States. Black outline indicates 662 the extent of the regions. Pale gray outline indicates the states within each region. Colored topographic 663 shaded relief is shown in the background. 

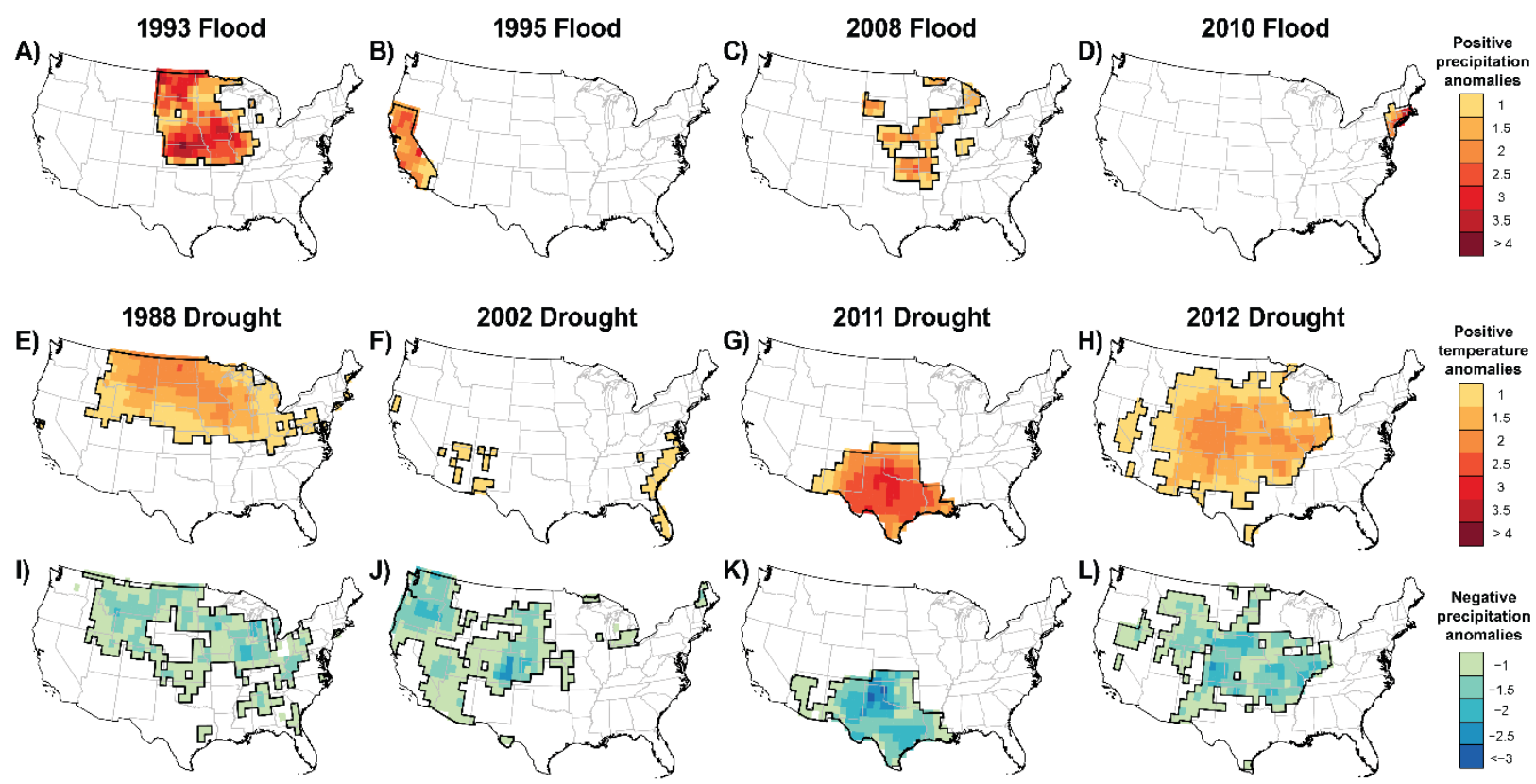

664

Figure 2. Location of the studied flood and drought events across the continental United States.

665

666

667

668

669

670

671

672

673

674

675

676

Computed climatological anomalies are indicated as red shades for temperature, and as blue shades for precipitation. Thick black outline indicates the spatial extent of the event. Color intensity indicates the anomaly of the observed climatology for the given season (greater than 1 or less than -1), as calculated on a pixel-by-pixel level across the entire United States. (A) 1993 July-August Flood, precipitation anomalies. (B) 1995 January-March Flood, precipitation anomalies. (C) 2008 June-August Flood, precipitation anomalies. (D) 2010 March Flood, precipitation anomalies. (E) 1988 June-August Drought, temperature anomalies. (F) 2002 March-November Drought, temperature anomalies. (G) 2011 March-August drought, temperature anomalies. (H) 2012 May-August drought, temperature anomalies. (I) 1988 June-August Drought, precipitation anomalies. (J) 2002 March-November Drought, precipitation anomalies. (K) 2011 March-August Drought, precipitation anomalies. (L) 2012 May-August drought, precipitation anomalies. 


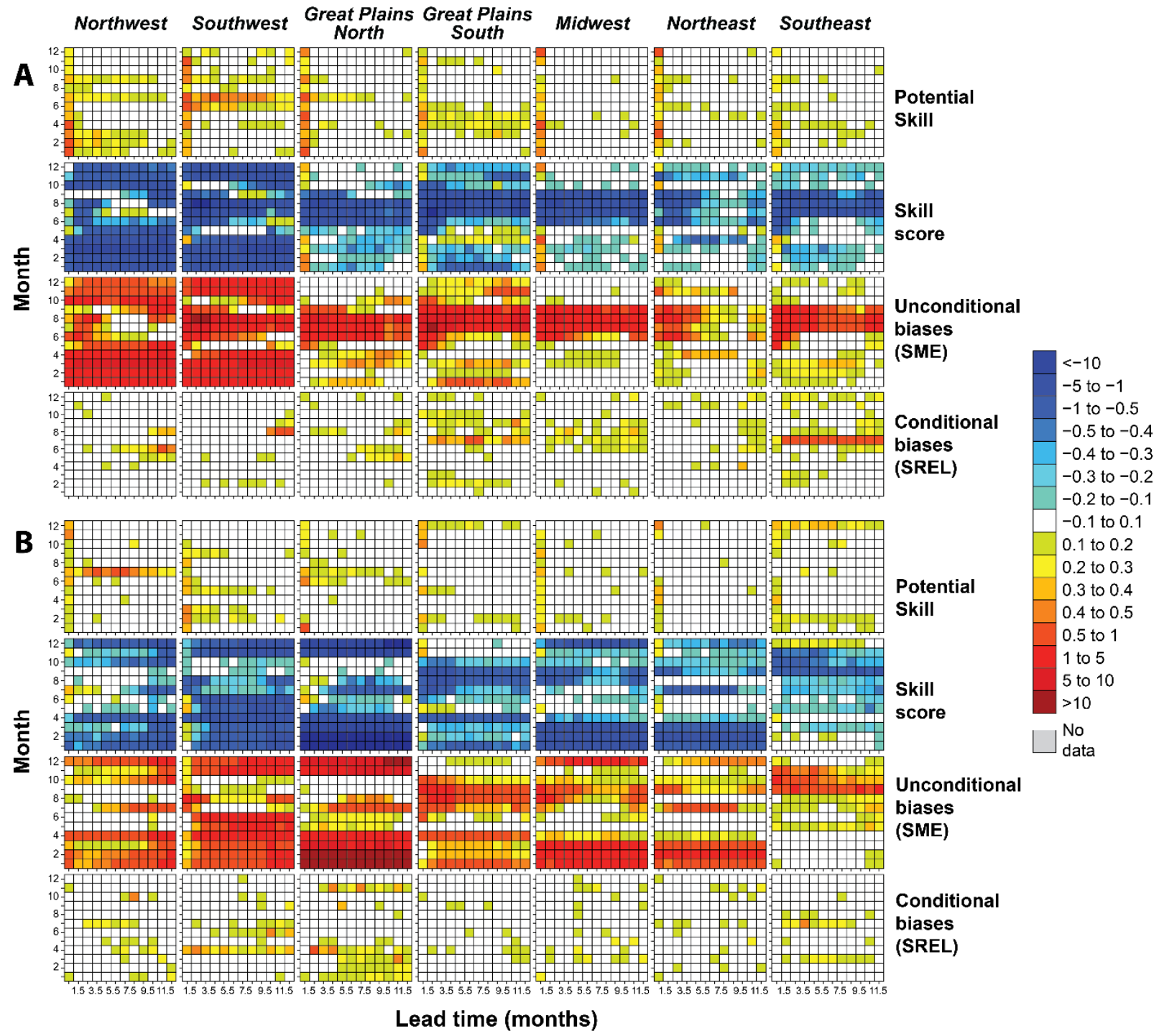

678 Figure 3. Color maps indicating average skill of the eight-model ensemble mean for (A) Temperature

679 and (B) Precipitation. For each individual color map (1 box), x-axis indicates the lead time of the climate

680 forecast, ranging from 0.5 to 11.5 months; $y$-axis indicates the month that is forecasted, ranging from 1

681 (January) to 12 (December). Labels at the top of the figure indicate each of the 7 regions shown in Figure

6821 (Northwest, Southwest, Great Plains North, Great Plains South, Midwest, Northeast, and Southeast).

683 Right side of the figure indicates the computed components of the ensemble's skill: Potential skill, Skill

684 score, Unconditional biases (SME), and Conditional biases (SREL). The color scale on the right side of the

685 figure is used for all components of the skill score, and ranges from less than -10 (blue shades) to more than

68610 (red shades). 

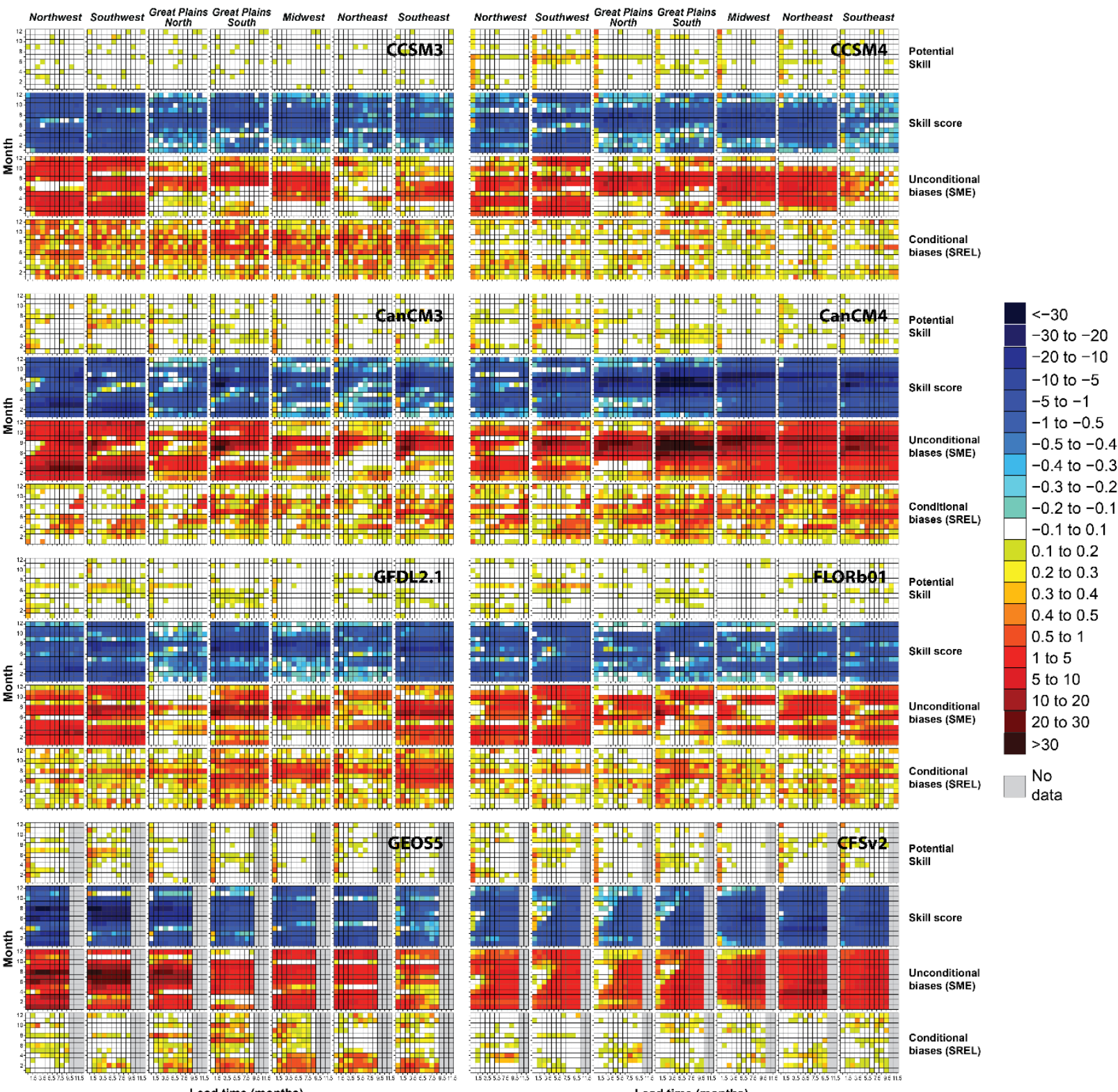

Lead time (months)

Lead time (months)

689 Figure 4. Skill of the eight individual GCMs in forecasting temperature (CCSM3, CCSM4, CanCM3,

690 CanCM4, GFDL2.1, FLORb01, GEOS5, and CFSv2). The layout of the panels is the same as described in

691 Figure 3. Note that GEOS-5 and CFSv2 only have 9 and 10 lead times, respectively, in comparison with

692 the other models. 

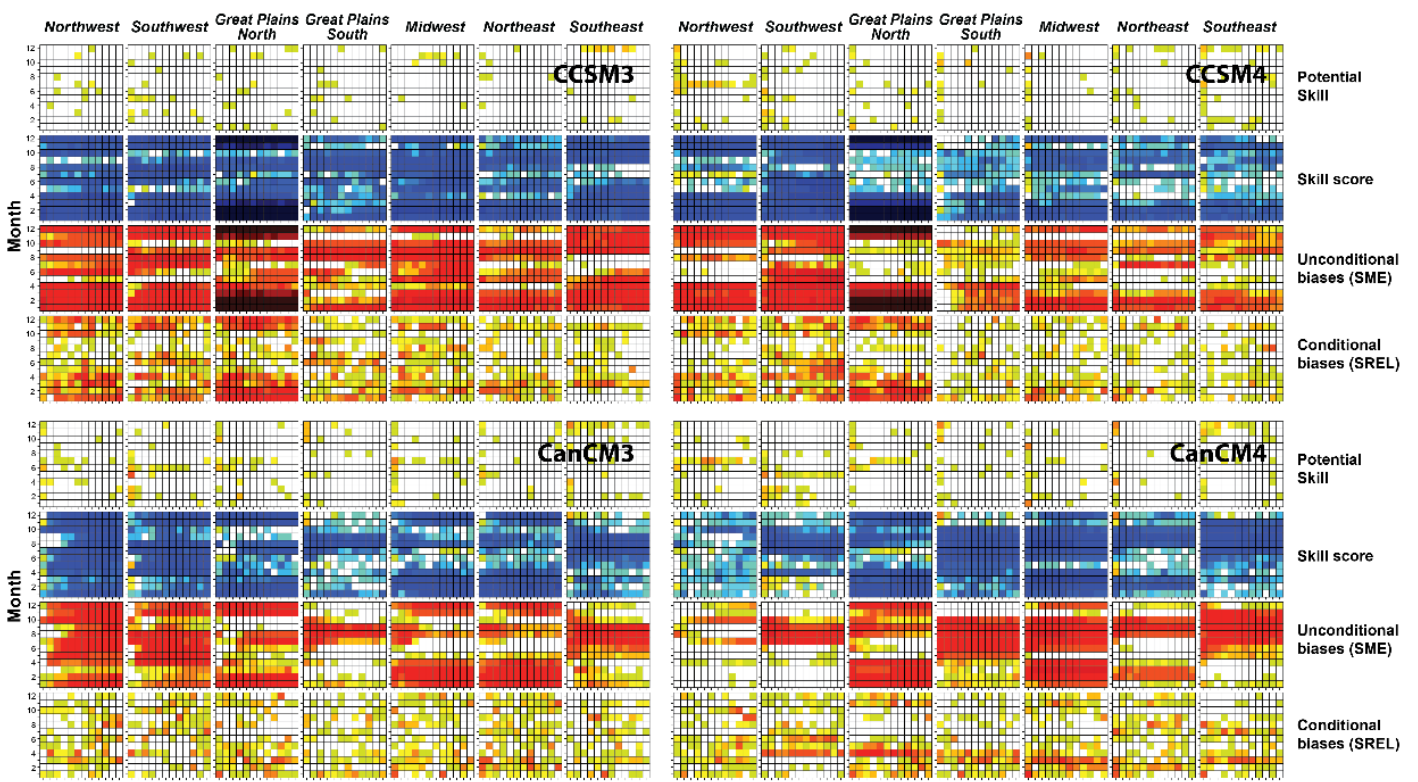

blases (SREL)
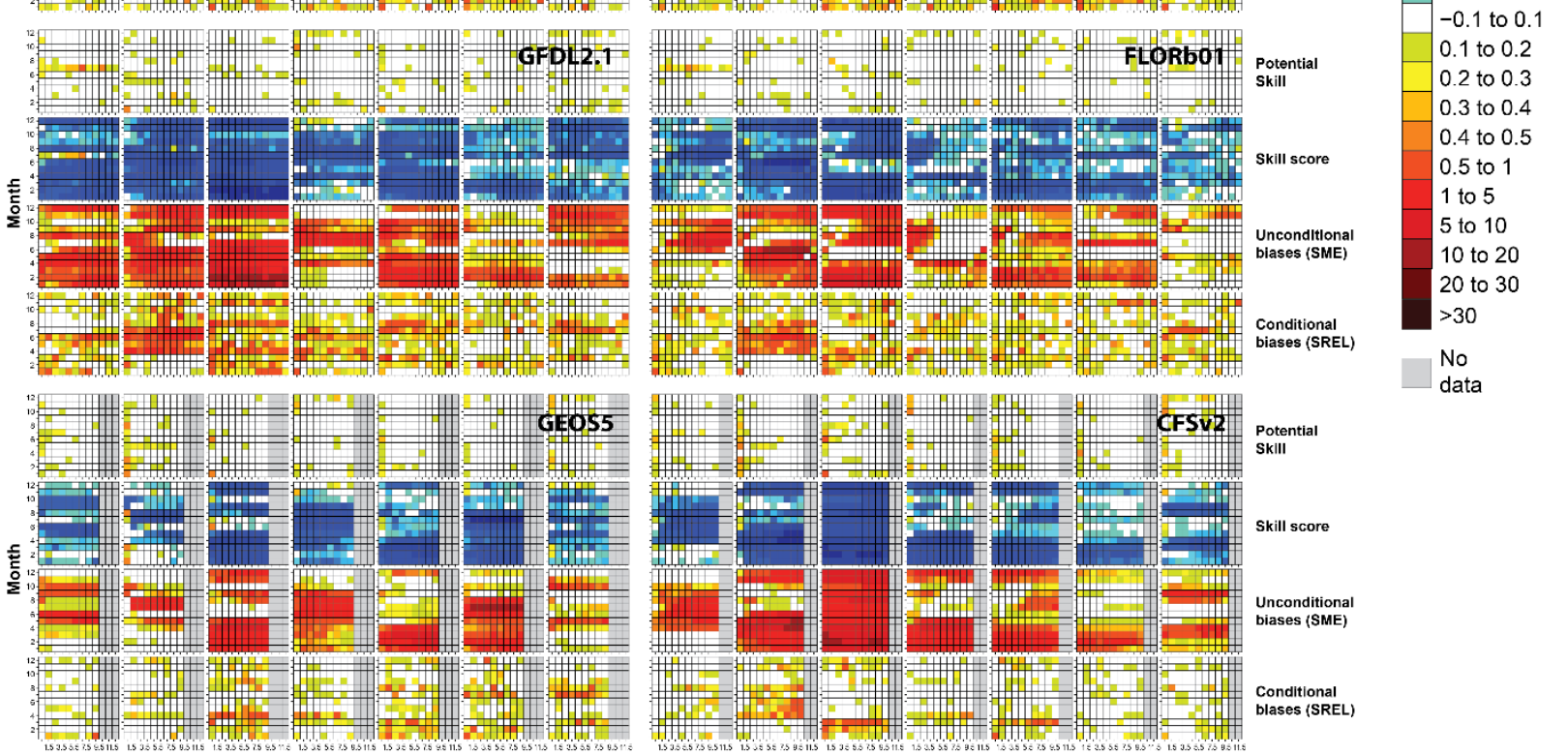

Lead time (months)

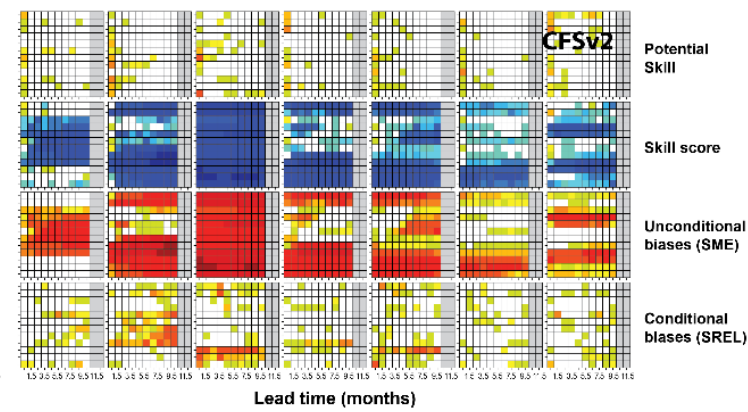

$<-30$

-30 to -20

-20 to -10

-10 to -5

-5 to -1

-1 to -0.5

-0.5 to -0.4

-0.4 to -0.3

-0.3 to -0.2

-0.2 to -0.1

-0.1 to 0.1

0.2 to 0.3

0.3 to 0.4

30

data

694 Figure 5. Skill of the eight individual GCMs in forecasting precipitation. (CCSM3, CCSM4, CanCM3,

695 CanCM4, GFDL2.1, FLORb-01, GEOS5, and CFSv2). Layout of the panels is the same as described in Figure 4. 


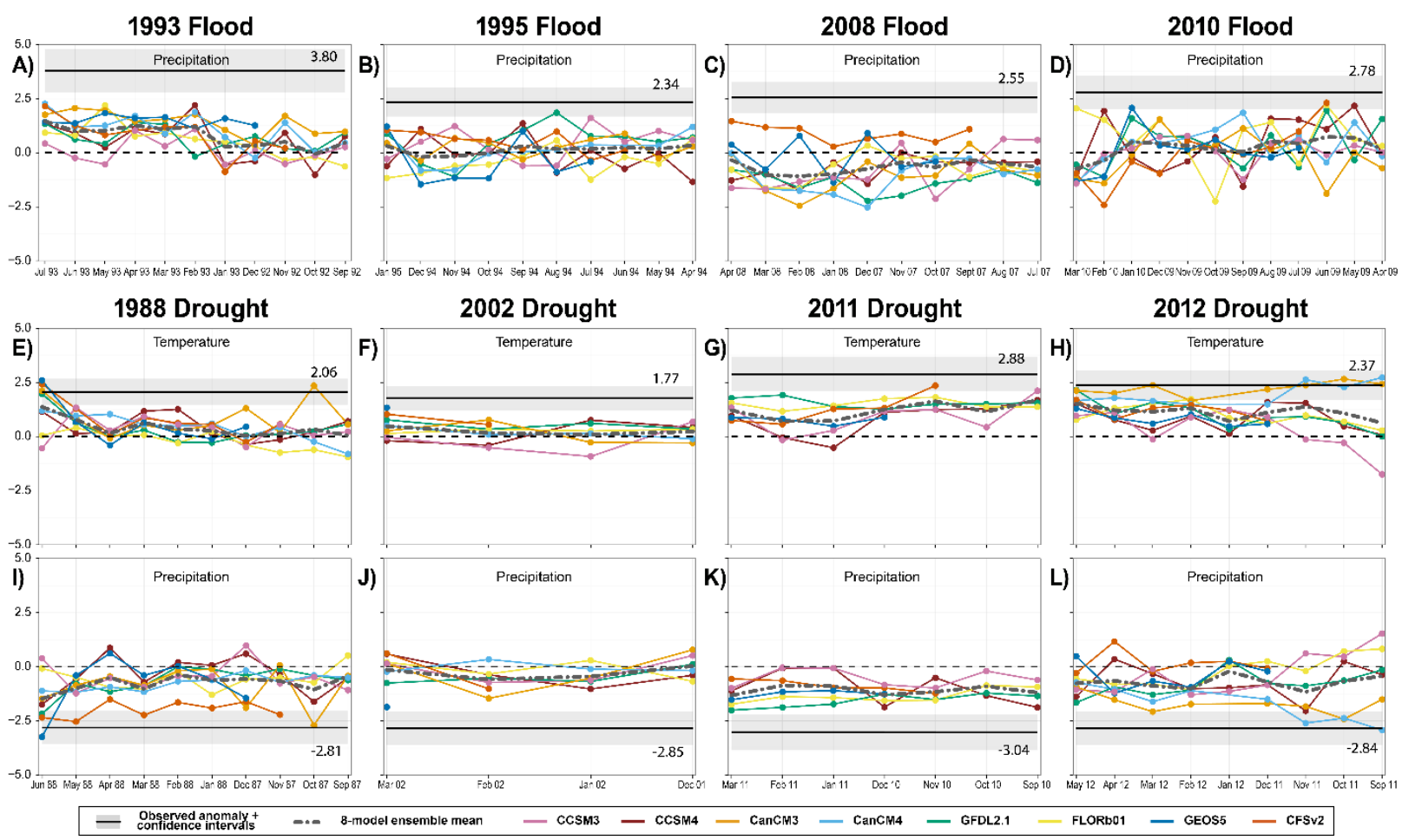

698 Figure 6. Skill of the eight NMME models in predicting four flood and four drought events, in

699 comparison with the observed climatology. Flood and drought events (A-L) are the same as in Figure 2.

700 Thick horizontal black line indicates the PRISM observed climatological anomaly, with 95\% confidence

701 intervals indicated as shaded grey rectangles in the background. NMME anomalies are indicated as colored

702 lines. Long/short-dashed black line indicates the eight-model ensemble mean. Panels F and J: note that

703 GEOS5 only exhibits one lead time and CFSv2 two, because the event lasted for nine months and these

704 models only issue nine- and ten-month lead times, respectively. Panels G and K: note that the two Canadian

705 models have data gaps in 2011, so are not included in the evaluation of the 2011 March-August drought. 